Article

\title{
Enemy Encounters in the War Poetry of Wilfred Owen, Keith Douglas, and Randall Jarrell
}

\author{
Michael Sarnowski \\ Department of English, Liverpool Hope University, Taggart Ave, Liverpool L16 9JD, UK; \\ michaelsarnowski@gmail.com
}

Received: 30 August 2018; Accepted: 11 September 2018; Published: 14 September 2018

\begin{abstract}
While some war poets amplify the concept of anonymity for enemy soldiers, projecting an "us vs. them" mentality, other defining voices of war counter this militaristic impulse to dehumanize the enemy. This pivot toward describing the World Wars more like humanitarian crises than an epic of good and evil is most notable in poems that chronicle both real and imagined close-range encounters between combatants. The poem "Strange Meeting" by British First World War soldier Wilfred Owen uses the vision of two enemy soldiers meeting in hell to reinforce his famous notion that war is something to be pitied. As a result of technological advancements in the Second World War and the increasing distance of combat, the poems "Vergissmeinnicht" and "How to Kill" by British Second World War soldier Keith Douglas wrestle with dehumanizing the enemy and acknowledging their humanity. "Protocols" by American Second World War soldier Randall Jarrell is an imagined view of civilian victims, and is a reckoning with the horrors human beings are capable of committing.
\end{abstract}

Keywords: First World War; Second World War; Wilfred Owen; Keith Douglas; Randall Jarrell; war poetry; distance; soldiers; enemies; encounters

Carrying waning traditions forward, such as presenting the enemy as anonymous, monstrous figures, as Robert Graves does in his elegiac "Goliath and David," is a trope that faded over the course of the First World War (Fussell 1975, p. 78). With the enemy presented as an overwhelming Goliath, Graves positions a "calm and brave" (Graves 1918, "Goliath and David" 37) fellow soldier as a pure-of-heart underdog whose "Scorn blazes in the Giant's eye" (Graves 1918, "Goliath and David" 27). While some major poets of the First World War such as Robert Graves amplified the concept of anonymity for enemy soldiers, projecting an "us vs. them" mentality, other defining voices of World War poetry countered this militaristic impulse to dehumanize the enemy. This pivot toward describing the war more as a humanitarian crisis than an epic of good and evil is most notable in poems that chronicle close-range encounters between combatants. The poem "Strange Meeting" by British First World War soldier Wilfred Owen uses the vision of two enemy soldiers meeting in hell to reinforce his famous notion that war is something to be pitied. As a result of technological advancements in the Second World War and the increasing distance of combat, the poems "Vergissmeinnicht" and "How to Kill" by British Second World War soldier Keith Douglas wrestle with dehumanizing the enemy and acknowledging their humanity. "Protocols" by American Second World War soldier Randall Jarrell is an imagined view of civilian victims that forces readers to reckon with the horrors human beings are capable of committing.

Taking influence and encouragement from meeting Siegfried Sassoon while they were both on medical leave from the Western Front, Wilfred Owen utilized the experience of other soldiers in his poetry as a mode of war commentary. Differing from Sassoon's portraits of life in the trenches for his fellow soldiers by recognizing the shared humanity of an enemy soldier, Owen's 1918 poem "Strange Meeting" is an example of compassion which begins with a movement mimicking Dante's 
journey into the depths of hell in Inferno. Owen's speaker escapes battle through a tunnel (by dying we can presume, though actual tunnel systems were used to support the trenches through troop and supply movement) where he comes across the body of a dead enemy soldier and realizes "we stood in hell" (Owen 1986, "Strange Meeting" 10). To console the dead soldier, the speaker says "Here is no cause to mourn," a consolation which sets the stage for the dead soldier's response to carry the remainder of the poem (Owen 1986, "Strange Meeting" 14). Just as the literal warning sign Dante passes upon his entry to hell reading "abandon all hope, ye who enter here," the dead soldier challenges the speaker by arguing for what has been lost as a consequence of war (Alighieri 1999, "Canto III" 7). For it is "the undone years [ ... ] Whatever hope is yours" and the hunt for "the wildest beauty in the world" which has been lost in the eyes of the enemy soldier (Owen 1986, "Strange Meeting" 15-16, 18). Sassoon attempted to inject impartiality by distancing himself and writing of the plight of other soldiers, while Owen uses the enemy soldier as a conduit to express the same message that threads through many of his most recognized poems: the loss of youth and "the pity of war" (Owen 1986, "Strange Meeting" 25). The irony of this moment is that the similarities recognized between Owen's speaker and this enemy combatant are only learned when they meet face to face in death. "Strange Meeting" reflects trench warfare, a mode of combat in which oppositional sides remained tucked away from one another in dug out channels, because in both the poem and fighting from trenches the oppositional soldiers typically only saw one another when one side charged over the top of the trenches to try and advance position, a time which ultimately was the moment of death for hundreds of thousands of soldiers. To confront one another in close combat, soldiers are reminded that the opposition is human and the violence committed is done with a degree of intimacy. According to the dead enemy soldier in "Strange Meeting," they are mourning "the pity war distilled," a statement which rightfully personifies war as a damaging force that the two figures of the poem have learned the brunt of first hand (Owen 1986, "Strange Meeting" 25).

Most of "Strange Meeting" is portioned out to the opposition, giving voice to the usually anonymously depicted enemy soldier, an act of compassion and humanity by Owen that is rarely displayed in First World War poetry. It is easier to train soldiers to carry out orders when they have absolved themselves of individualism and view themselves as part of a collective, or in other words, "the Army's high command to imposing an institutionally-sanctioned collective identity upon the mass of soldiers" (Lukasik 2008, p. 197). The same anonymization happens when soldiers view the enemy as a collective evil rather than an army of individuals with their own thoughts, histories, and aspirations. Regardless of the inspiration for Owen to write about this meeting-either literal and drawn from the experience of encountering a dead enemy soldier, or figurative as an imagined encounter of two deceased soldiers meeting in hell-he is cultivating a sense of empathy for the enemy and contextualizing the nature of the conflict within geopolitical aims and not personal motivations. More notable to Owen than their differences in nationality is the fact that they share and embody a history of warfare that leaves mankind either "content with what we spoiled" (Owen 1986, "Strange Meeting" 26) or they will be "discontent, boil bloody, and be spilled," suggesting that they are either complicit with the human and emotional costs of war or are at risk of being killed by a complicit opposition (Owen 1986, "Strange Meeting" 27). The final stanza conveys the heightened moments of closeness when we learn that the second speaker is not only an enemy soldier, but one who was killed by the first speaker, and recalls the reaction of the first speaker in the act of killing: "I am the enemy you killed, my friend./I knew you in this dark for so you frowned/Yesterday through me as you jabbed and killed" (Owen 1986, "Strange Meeting"40-42). This possible description of a bayoneting, an act that brings two combatants close enough to touch, is a stark difference from the distance of bullets and shells fired from one trench to another. Owen establishes a parallel between the closeness of combat and the oft-ignored similarities of combatants. Owen is not suggesting that they share political aims or personal goals, but that they are one-in-the-same, both cogs in the bloodied wheels of warfare throughout history, an image he presents with the archaic description of "when blood had clogged their chariot-wheels/I would go up and wash them from the sweet wells," implying that his role as a 
soldier is to keep the wheels of war moving (Owen 1986, "Strange Meeting" 34-35). By intentionally referencing the use of a chariot, Owen is speaking about war in the twentieth century as if it is no different from the battles fought by the Roman Empire. Despite technological advancements from the chariot wheel to the continuous track of tank wheels, Owen is making the case that war is still war, and the killing of others that it entails is all the more harrowing when conducted at a range close enough to console someone.

The brutal legacy of the close combat of trench warfare in the First World War is a strategy that is largely abandoned in the Second World War. Not only are the Battle of the Somme and Verdun reminders of catastrophic casualties from failed strategies, but the technological advancements that are made in the interwar period drastically change the way war is conducted. This shift toward the heavy utilization of air attacks, while still fighting on land and sea, produced a change in mindset for combatants. As explained by Diederik Oostdijk, "The mechanized, industrialized nature of modern warfare had eroded the possibility of heroic dueling, and according to the World War II poets, heroic agency thus belonged to the past" (Oostdijk 2011, pp. 30-31). For this reason, there are fewer Second World War poems that capture the same close-range observations between combatants such as those made by Owen and Sassoon. Nonetheless, there are poets who chronicle the transition of warfare between close range and far distances. Keith Douglas was a member of the British tank corps who primarily served in the North Africa campaign and died in the invasion of Normandy. Douglas' poem "Vergissmeinnicht" follows in the tradition of Owen's "Strange Meeting" in that it personalizes and humanizes the enemy by acknowledging their loved ones.

Coming close enough to the dead enemy soldier to rummage through his personal belongings, Douglas' speaker finds "the dishonoured picture of his girl/who has put: Steffi. Vergissmeinnicht," which translates as "forget me not" (Douglas 2011, "Vergissmeinnicht" 10-11). Though Douglas jeers the dead soldier for the rigor mortis that has set into his "equipment," the poem exhibits sympathy for the loved ones who will experience the loss of this soldier (Douglas 2011, "Vergissmeinnicht" 15). This recognition of the service and emotional weight of non-combatants is relatable for many soldiers, but until the Second World War this had not been a thoroughly explored topic in war poetry by soldier-poets themselves. There is a case to be made that non-combatants who wrote during the First World War addressed war from the perspective of life away from the front lines, including war nurses like Vera Brittain and Mary Borden who tend not to receive the same attention or acclaim as male poets, including civilians like Rudyard Kipling, Thomas Hardy, and D.H. Lawrence. While many First World War soldier-poets allude to the ignorance of non-combatants and describe their naivety toward the realities of war, the poetry of combatants during the Second World War is a historically underrepresented field compared to that of civilians. In "Vergissmeinnicht," Douglas draws our attention to the dead enemy soldier's lover Steffi, contrasting her loss with the soldier's undignified death, remarking "she would weep to see today/how on his skin the swart flies move" (Douglas 2011, "Vergissmeinnicht" 17-18). Though the enemy soldier has been killed, it is his lover Steffi who will undergo "mortal hurt" (Douglas 2011, "Vergissmeinnicht" 24). Douglas struggles to humanize the enemy, but he recognizes the humanity of the loss as experienced by the loved ones of combatants. However, this compassion only comes to fruition because of the intimate interaction of sifting through enemy soldier's valuables, and being forced to recognize the enemy as human by learning of their life outside of the war.

More characteristic of Second World War poetry, Douglas' "How to Kill" is a poem which offers the distanced perspective of a tank officer scouting an enemy soldier through a tank periscope. It is through the angled sight that the speaker zeroes in on his soon-to-be victim, remarking "Now in my dial of glass appears/the soldier who is going to die" (Douglas 2011, "How to Kill" 7-8). Similar to "Vergissmeinnicht," "How to Kill" is an invasion of privacy where the enemy soldier is unaware he is being watched as "he smiles, and moves about in ways/his mother knows, habits of his" (Douglas 2011, "How to Kill" 9-10). Again, the focus momentarily shifts from the battlefield to the home front, as the enemy soldier is described by the absence he has left in the home life of his 
family. When the speaker orders the shot to be taken, the enemy soldier's absence from the ranks of the living is described in simplistic terms: "Death ... has made a man of dust/of a man of flesh" (Douglas 2011, "How to Kill" 12-14). Sympathy for the family of the soldier evaporates just as quickly, as the extinguishing of life is self-congratulatory, referred to as "sorcery" and an act that causes the speaker to feel "amused/to see the centre of love diffused/and the wave of love travel into vacancy" (Douglas 2011, "How to Kill" 14, 15-17). In amazement, the speaker acknowledges "How easy it is to make a ghost" (Douglas 2011, "How to Kill" 18) and describes the act of killing as where "man and shadow meet" (Douglas 2011, "How to Kill" 22). The cumulative effect of this commentary on executing an enemy soldier is how distance influences one's response to culpability and guilt. In contrast to the sustained recognition of loved ones left behind in "Vergissmeinnicht," the undercurrent of "How to Kill" lies in the fascination with the ease of killing, while the distance between killer and victim in turn keeps emotions at a distance.

Furthermore, Douglas's emotional void is conveyed without any mention of the weaponry itself. The only technological tool mentioned in "How to Kill" is the periscope, and it shortens the distance between the speaker and the enemy soldier without feeling the level of human connection found in "Vergissmeinnicht." "How to Kill" is an impersonal poem about killing, and it is the heightened mechanization of war that makes this possible. Soldiers in the Second World War learned to deal with advancements in weaponry that made killing from great distances possible, while maintaining minimal risk for the perpetrator. For this reason, as Peter Lowe suggests in his analysis of Keith Douglas, "modern war poetry often seeks out the dissonance between Homer's text and the near-mechanised slaughter of the Western Front" and that twentieth-century war poets possess a "distrust of anything that seeks to make war sound more elevated than it is" (Lowe 2014, p. 301). Similar to this characterization of Douglas, Siegfried Sassoon also defended against this elevated view of war, challenging the opinions of non-combatants, about whom he writes in "How to Die":

You'd think, to hear some people talk,

That lads go West with sobs and curses,

And sullen faces white as chalk,

Hankering for wreaths and tombs and hearses. (Sassoon 1984, "How to Die" 9-12)

Sassoon refutes the idea that soldiers were eager to ship off to war and die for their country. Lorrie Goldensohn suggests that Douglas' "'How to Kill' is the successor of Siegfried Sassoon's 'How to Die,'" a parallel that acknowledges that the movements of action and repercussion swing in both directions (Goldensohn 2003, p. 128). In the tradition of Owen and Sassoon, Douglas chronicled his Second World War experience with simplicity and directness. As implied in its title alone, "How to Kill" is a commentary devoid of a sense of glory. By making the reader complicit in the act by describing the mindset and action taken, neutrality is removed. Effectively, war poems that chronicle death in detail force readers to accept a broader view of the war; to support the war is to support the acts of brutality it fosters, and one cannot reap victory without consenting to the death of others. Though Goldensohn describes "How to Kill" as being written with a "sober decency" for its plain speech when compared to the grotesque details of Sassoon's poetry, "How to Kill" is proof of an emotionally callused speaker (Goldensohn 2003, p. 128). The speaker in "How to Kill" is detached from the act not only by distance, but in the acknowledgement of how little effort is necessary to kill. In the poem's closing lines, "A shadow is a man/when the mosquito death approaches," Douglas intentionally uses a blood sucking insect to convey his idea that such a seemingly insignificant thing-an insect bite, like a trigger pull—can cause the transition from life to death (Douglas 2011, "How to Kill" 23-24). Rather than depicting a typical heroic act of defence, "How to Kill" is a matter-of-fact, proactive, procedural retelling of the ease of killing from the point of view of the aggressor. Douglas uses distance as a barrier between the speaker and feelings of guilt, remorse, or shame, and instead capitalizes on the absence of these feelings that result from being compliant in the murder of a soldier from afar. 
Since "How to Kill" is a direct poem, it seems unlikely that Douglas is using distance as a coping mechanism to dissociate his feelings from his actions, and more probable that he is grappling with the unexpected speed and relative technological ease with which war is now fought. With models in Owen and Sassoon writing First World War poems that captured the pressure and relentlessness of trench warfare, Douglas seems caught off guard by how little engagement is necessary to accomplish the goal of killing the enemy. This stunned response to the literal distance between combatants and the figurative distancing that occurs when the enhanced mechanization of war challenges the conventional relationship and emotional engagement of soldiers during combat, a concern shared by the American Second World War poet Randall Jarrell.

Despite being one of the most recognizable American poets of the Second World War, Randall Jarrell did not see first-hand action, a circumstance that would shape his writing. As a celestial navigator and flight instructor in the US Army Air Force, Jarrell's poetry resisted Auden's suggestion that a war poet "can only deal with events of which he has first-hand knowledge" (Oostdijk 2011, p. 110). Jarrell used his distance from Second World War battles as an asset and took a creative approach to his subjects, including drawing his attention to soldiers away from battle (either seeing the war from above or from training grounds in the US), to women and children civilians, and to Holocaust victims, oftentimes speaking on behalf of "those who cannot testify for themselves" (Gubar 2006, p. 23). By presenting thoughts from this unique perspective of both participant and outsider-balancing the closeness to troops, machinery, and strategy with the distance from battle-Jarrell's poems speak to war mechanization and distance by focusing on the machinery of the State, that of both allies and enemies. Similar to the concept that the soldier is a pawn acted upon by the State, as Jarrell's "The Death of the Ball Turret Gunner" accomplishes in the transition from birth to death and armed service to sacrifice, Jarrell's assembly-line descriptions of the path from enlistment to death paint the duty of soldiers as a submissive act, marionettes whose strings are controlled by the State. As a result, enemy soldiers are largely absent from Jarrell's poems, and therefore his encounter with the enemy is through the imagined experience of those who were their victims, such as the children and families being taken to a concentration camp in "Protocols."

Though consistently critical of the State and military of which he was a part, Randall Jarrell was not averse to defining the Second World War as a conflict that needed to be fought. Jarrell's greatest justification and support for the defence against the Axis Powers come in the form of empathic poems on the civilians victimized by war. Jarrell's poem "Protocols" is an example of the compassion he held for others by giving voice to child victims of the Holocaust and, having appeared in a 1945 issue of Poetry, may be the first American poem published on the topic of the Holocaust (Flanzbaum 1998, p. 260). "Protocols" vacillates between the voices of two children taken by train from Odessa to a concentration camp. There is no judgment, only recollection, as the children's observations exude innocence and the unknowable horror they are about to encounter. The two voices are denoted as one in plain text and the other italicized. Here is the poem in its entirety:

We went there on the train. They had big barges that they towed,

We stood up, there were so many I was squashed.

There was a smoke-stack, then they made me wash.

It was a factory, I think. My mother held me up

And I could see the ship that made the smoke.

When I was tired my mother carried me.

She said, "Don't be afraid." But I was only tired.

Where we went there is no more Odessa.

They had water in a pipe-like rain, but hot;

The water there is deeper than the world 
And I was tired and fell in my sleep

And the water drank me. That is what I think.

And I said to my mother, "Now I'm washed and dried,"

My mother hugged me, and it smelled like hay

And that is how you die. And that is how you die. (Jarrell 1981, "Protocols")

The regimented form of three quintet stanzas in which slant rhymes between the children's voices such as "squashed" / "wash," "towed" / "smoke," and "dried" / die" ricochet off of one another to create a sense of cohesion and order that mirrors the movement of Holocaust victims. This imagined memory of the children depicts the systematic operation of The Final Solution in plain, simple speech. "We went there on the train" (Jarrell 1981, "Protocols" 1) one child says at the outset of the poem, to which the other child adds "there were so many I was squashed" referring to the overcrowded trains shipping Jews to the camps (Jarrell 1981, "Protocols" 2). Upon arrival at the camps, the first child notices a smoke-stack, "It was a factory, I think," the awful irony being that the child is right to associate the image of a smoke-stack with a factory, unaware that they are the raw material and the end product is death (Jarrell 1981, "Protocols" 4). The first speaker recalls that "they made me wash," also unaware that the lie of the shower was the precursor to death in the gas chambers, a misdirection sustained until the last moments of life, just as the cruelty of faux-inspirational signs such as "Arbeit macht frei" (work sets you free) were placed at the entry of many concentration camps (Jarrell 1981, "Protocols" 3). The double meaning of this act of cleansing, literal and ethnic, makes the pending betrayal all the more appalling. All the while, the children in "Protocols" tell us of the efforts made by their parents to free them from fear, as one child is held up by their mother so they "could see the ship that made the smoke" (Jarrell 1981, "Protocols" 5) while the other is told "Don't be afraid" (Jarrell 1981, "Protocols" 7).

To understand the power of this historical moment is to recognize the ease with which image association paints a scene of dread so quickly. In the first stanza, by learning that the speakers are on a "train," "squashed" with people, and their destination is a factory-like area with a "smoke-stack," like a game of word association, many would leap to visions of the Holocaust. However, Jarrell does not say it himself, nor does he mention the war, the year, or any biographical detail other than "Where we went there is no more Odessa," a reference which could be absorbed as a definitive detail to confirm the poem's subject (Jarrell 1981, "Protocols" 8). Jarrell embodies the voices of children he never met to bring the darkest acts of the war to his readers, and in doing so eliminates the buffer between safe citizens and victims. By removing the literal distance between reader and victim, mimicking that closeness with the claustrophobic descriptions of Jews overcrowded in train cars, Jarrell transfigures distance to document the industrialized destruction of people. Just as soon as these puzzle pieces begin to reveal the true nature of the children's testimonials, the poem concludes with naivety, tenderness, and admission. The children go into the showers with their families and feel consumed by the water, "The water there is deeper than the world ... the water drank me" (Jarrell 1981, "Protocols" 10, 12). The first child follows orders, says "Now I'm washed and dried" and is hugged by their mother (Jarrell 1981, "Protocols" 13). In the harrowing final step of the eradication of the children, both voices say "And that is how you die," a haunting echo that simultaneously brings mass suffering down to the level of the individual while the repetition of the line ensures we do not forget that this is a story that happened over and over (Jarrell 1981, "Protocols" 15). In contrast to Owen's "Strange Meeting" and Douglas's "Vergissmeinnicht" and "How to Kill," Jarrell's "Protocols" is a poem in which soldiers are absent altogether. Jarrell recognizes the importance of seeing these events through the eyes of child victims, defenceless against the Nazi apparatus. This concept is heightened by the subsequent absence of weaponry, as the civilians being transported to their deaths are not armed from a distance in a tank like the speaker in "How to Kill," nor are they armed like the soldiers in "Strange Meeting" had been with their guns and bayonets. As much as this immense horror tells us about the innocence and naivety of the children who voice "Protocols," it levies equally damning criticism of the unseen, unheard enemy perpetrators. Those capable of genocide-whether the Nazi hierarchy or varied ranks 
of officers, guards, and ordinary executioners-are portrayed not by their presence in "Protocols," but by their ominous omission.

To mechanize the murder of civilian populations in wartime, the Nazi regime instituted protocols to structure their attempt to eradicate the Jewish people. The contrast created by having a poem titled "Protocols," defined as "the official procedure or system of rules governing affairs of state or diplomatic occasions" ("Protocol" n.d.), and having this systematic procedure shown through the eyes of innocent children highlights the inhumanity of the process being described. As outsiders, the closeness that Jarrell brings us to this horrible reality is described by Lorrie Goldensohn, who suggests that "parts of the reader-writer contract ask that we, altogether too safe outside the text, not be made voyeurs of pain and that we not turn too expeditiously away from the children to examine ourselves" (Goldensohn 2003, p. 216). Though any document on the Holocaust will be emotionally impactful, Goldensohn is arguing that the importance of Jarrell's "Protocols" is that it strikes a balance between drawing our attention to the suffering of others, while showing caution not to veer so hard in the direction of the grotesque and thereby push readers away from viewing the speaking children as if they could be their own. Particularly when considering the 1945 publication date, "Protocols" has deep emotional potential when one considers how awareness of the depravity of the Holocaust was spreading, though the full scope would take years and lifetimes to learn and process.

Randall Jarrell's poem "Protocols" speaks to the overarching order of war, though it is seemingly antithetical to describe war as orderly when all impulses point to it being a chaotic agent of change. Nonetheless, the mechanization of weaponry, strategy, and the systematic control of soldiers and civilians that occurred with the onset of the World Wars is undeniable. In "Protocols", Jarrell is shortening the distance between the realities of the Second World War and the reader, and does so by invoking comprehensible details and the observations of children forced to a concentration camp. In doing so, Jarrell breaks down the Second World War into details that uninvolved readers can understand, and which will allow them to emotionally connect to the suffering of others. Ultimately, the development of empathy is key to the resonance of these poems, just as identified in Wilfred Owen's "Strange Meeting" and Keith Douglas' "Vergissmeinnicht" and "How to Kill." In Owen's "Strange Meeting," the close proximity of trench warfare is a catalyst for a thoughtful encounter between deceased enemy combatants. In Douglas' "Vergissmeinnicht," similar to "Strange Meeting," a British soldier comes upon a deceased enemy soldier, and upon going through his personal belongings becomes cognizant of the loved ones who will feel the brunt of his death. The same detached sense of empathy is conveyed in "How to Kill," where the speaker is more so in disbelief over how easy it is to take a life than he is concerned with killing his enemy, and how that human fragility will be felt by the enemy soldier's mother.

Each of these poems humanize others and bring the fragility of human life to a closeness that makes it impossible to avoid, regardless of nationality or cause. Utilizing as fluid a concept as distance in war poetry and extending the focal point beyond the suffering of soldiers is a more encompassing approach to analysing the complexities of war. By manipulating the way distance is used, the traditions of war poetry are disrupted because it makes readers complicit in the actions of war. This shift towards exposing readers to the battlefield experience and the degrees of inner turmoil of soldiers was particularly notable in First World War poetry because of the way war was fought at close range and in trench-laced fields. With the further change in Second World War combat, where greater damage could be done from greater distance and population centres became military targets, the importance of maintaining a sense of intimacy in war poetry is heightened because such irrevocable and divisive behaviour leaves less room for blind patriotism. Following the groundwork laid by Wilfred Owen, Keith Douglas and Randall Jarrell use empathy and varying levels of distance to remind non-combatants of the true cost of war, and to show that permissiveness of nations to conduct war comes at a moral price. 
Funding: This research was funded by a Vice-Chancellor's PhD Scholarship at Liverpool Hope University.

Conflicts of Interest: The author declares no conflict of interest. The founding sponsors had no role in the design of the study; in the collection, analyses, or interpretation of data; in the writing of the manuscript, and in the decision to publish the results.

\section{References}

Alighieri, Dante. 1999. Canto III. In The Inferno of Dante: A New Verse Translation. Translated by Robert Pinsky. New York: Noonday.

Douglas, Keith. 2011. How to Kill, Vergissmeinnicht. In The Complete Poems. London: Faber and Faber.

Flanzbaum, Hilene. 1998. The Imaginary Jew and the American Poet. ELH 65: 259-75. [CrossRef]

Fussell, Paul. 1975. The Great War and Modern Memory. New York: Oxford University Press.

Goldensohn, Lorrie. 2003. Dismantling Glory: Twentieth-Century Soldier Poetry. New York: Columbia University Press. Graves, Robert. 1918. Goliath and David. In Fairies and Fusilliers. New York: Alfred A. Knopf.

Gubar, Susan. 2006. Poetry After Auschwitz: Remembering What One Never Knew. Bloomington and Indianapolis: Indiana University Press.

Jarrell, Randall. 1981. Protocols. In The Complete Poems. New York: Farrar, Straus \& Giroux.

Lowe, Peter. 2014. Stripped Bodies and Looted Goods: Keith Douglas's Iliad. The Cambridge Quarterly 43: 301-24. [CrossRef]

Lukasik, Sebastian Hubert. 2008. Military Service, Combat, and American Identity in the Progressive Era. Ph.D. dissertation, Duke University, Durham, NC, USA, September 29.

Oostdijk, Diederik. 2011. Among the Nightmare Fighters: American Poets of World War II. Columbia: University of South Carolina.

Owen, Wilfred. 1986. Strange Meeting. In The Poems of Wilfred Owen. Edited by Jon Stallworthy. New York: W. W. Norton.

"Protocol". n.d. Oxford English Dictionary. Available online: https://en.oxforddictionaries.com/definition/ protocol (accessed on 1 April 2018).

Sassoon, Siegfried. 1984. How to Die. In Collected Poems, 1908-1956. London: Faber and Faber.

(C) 2018 by the author. Licensee MDPI, Basel, Switzerland. This article is an open access article distributed under the terms and conditions of the Creative Commons Attribution (CC BY) license (http:// creativecommons.org/licenses/by/4.0/). 